\section{Neil Mellor}

currently leads BT's eGovernment marketing initiative, having headed business Internet/intranet and eBusiness marketing in BT since 1996. A frequent speaker at conferences and events across Europe, Neil is an authority and influential presenter on eBusiness and Internet trends and their impact on large and small organisations, supply chains, business models and the economy. Neil is a past member of the IMRG (Interactive Media in Retail Group) Senate.

Keywords: eBusiness, intranet, networked economy

\section{Introduction stage}

Neil Mellor,

Head of eGovernment Marketing,

Telephone House,

153 Princes Street,

Ipswich, Suffolk IP1 1QB

Tel: +44 1977591552

E-mail: neil.2.mellor@bt.com

\section{Best Practice}

eBusiness in BT

\author{
Neil Mellor \\ Date received (in revised form): 18 August 1999
}

\begin{abstract}
Electronic business presents companies with the opportunity to capture and exploit tacit knowledge, dramatically reduce costs, improve and leverage customer relationships and improve revenue and shareholder value. It can transform not only the costs, but also the culture and therefore collaborative capacity and competitiveness of the business. BT's experience presents a valuable case study for businesses and a pointer to the future for British enterprises seeking to survive and compete in the networked community.
\end{abstract}

\section{Introducing eBusiness}

There's a revolution coming. This revolution doesn't involve an uprising or arms, but it does involve the uniting of the workforce and the dissemination of new ideas - it's a business revolution and it is centred around the Internet and the idea of electronic business (eBusiness) becoming a reality.

The pace of technological change is having a rapid and fundamental impact on organisations and business procedures, to a far greater extent than anything that has come before it. Of course, by itself technology could not hope to spark this 'revolution' in business. It is being supported by market drivers that are simultaneously changing people's perceptions about what is important within and outside their organisations, forcing them to look at new and faster ways to gain and maintain their competitive edge.

Business is subject to intense pressure and competition as companies seek to differentiate their products and reduce costs, while increasing revenues and profits in increasingly commoditised markets. To help companies meet these harsh new demands, critical success factors have emerged for organisations to adopt as they move away from traditional ways of doing business. Speed is one of them - supply chains need to deliver faster, new products must get to market quicker, share prices react instantly and business processes need to be able to anticipate and react in the face of increasingly rapid change.

This is where 'eBusiness' enters the equation. eBusiness, as the term suggests, is all about conducting business electronically. At BT we define eBusiness as the ability to get your people, suppliers and customers working together, sharing information and transacting electronically, making your organisation much more effective. To make this definition a reality is no mean feat and does not happen overnight. Companies need to put definable metrics and parameters in place if they are to realise the true benefits that eBusiness can deliver, as well as realising that it is a staged process that must start with the basics and progress from there towards a true eBusiness model.

Wherever you look in today's business landscape, in any sector and at every level, you will find businesses at different stages of eBusiness. At the 'introduction' stage, there are companies on their first forays into 


\section{Automation stage}

\section{Transformation stage}

\section{Overcoming the legacies}

eBusiness, implementing the initial Web or intranet applications, getting e-mail and communicating electronically.

This first wave of eBusiness is usually a response to the need to reduce costs within an organisation, and although business processes remain on a traditional footing, such companies are experimenting with new channels to market and gaining an early understanding of the potential benefits of eBusiness. Examples of such companies are widespread, particularly at the small and medium-sized enterprise (SME) level: a local car dealer taking Land Rover orders from Asia, a hotel in Lincolnshire showing its facilities to potential overseas visitors, an antiques dealer from the Cotswolds gaining customers from all over the globe at lower cost than it took to advertise in its local newspaper are just a few of the examples BT has worked with.

At the 'automation' stage, companies become more sophisticated as they overcome the technological hurdles and begin to gain an understanding of how eBusiness can really change and affect their organisation's performance. Here, companies are developing sophisticated websites with eCommerce capabilities, interactive content and dynamic links to back-office systems. Intranets are used for employee directories, sales records and payroll and they have growing extranets along their supply chains, developing leaner organisational structures geared to a fast, flexible response to market. Again, at this level examples abound - BT itself is involved in the automation stage of eBusiness, as are companies like Dell (which translated its direct selling business model to the World Wide Web (WWW) and now takes over 25 per cent of its orders online, at greatly reduced cost and with increased customer satisfaction).

Finally there are companies operating at the 'transformation' level of eBusiness. These archetypal eBusiness operations have recognised opportunities to (re)intermediate markets electronically over the Internet. They have recognised the crucial importance of 'intangible assets' (customer relationships, the strength of brands, close partnerships and trust) and disposed with traditional business processes and overheads. Notable examples of such companies include Egghead, the US retailer that closed its retail outlets across the country and moved entirely online, and Amazon.com, which is revolutionising the book-selling marketplace.

\section{BT's moves towards eBusiness - the intranet}

In the mid-1990s technologies emerged that were obviously making an impact on the process of conducting business. As the UK's second largest employer, with around 125,000 employees in the UK, Europe and the US, BT had long been aware of the challenges associated with simple communication across the company. There was also the associated cost of producing and updating standard company-wide information and distributing this to every BT office.

In 1993, it became apparent that employees were communicating via e-mail more and more. This had spread across the organisation, but an internal audit discovered that BT was using some 176 different variants of 13 messaging platforms. As a first stage towards business transformation, therefore, BT standardised in 1995 to the interface and protocols of the WWW. This was the first major step towards an 'intranet' - using a consistent Web browser and giving more people in BT access to this 
Mellor

\section{Standard Infrastructure}

\section{$£ 1.1$ bn economies}

\section{Cultural impact}

'private Internet' meant that information could be accessed in a live, dynamic, immediate and open way.

The BT intranet developed rapidly - the company identified that it provided a standard infrastructure on which both existing platforms and operating systems could internetwork, and on which new applications could be mounted easily to deliver increased business benefit. BT also set about identifying tangible business metrics and key performance indicators that an intranet could deliver on, both short-term economic and financial parameters, but just as importantly the longer-term social impact this would have on the employee base.

Tangible examples of what the intranet delivered include the Desktop Directory, which has swept away all of BT's old paper internal telephone directories. Users are now able to gain contact and position details of anyone in the company in seconds, using a normal Web browser. A search can even be carried out using just a person's first name, and particular functions or departments can also be located on the system.

\section{BT intranet's tangible results}

Specific features of the intranet, such as the Desktop Directory, may seem like perfectly logical and simple steps to put into place, but taken as a whole the financial impact that the intranet has made on BT is astronomical. By simply making policy documents available online and doing away with costly reproduction of paper-based documents, BT saves some $£ 20 \mathrm{~m}$ a year. Audits have also shown that the intranet (including e-mail) saved BT $£ 305 \mathrm{~m}$ in $1995-96$ and $£ 745 \mathrm{~m}$ in $1996-97$ - an incremental return on investment (ROI) of well over 1,000 per cent.

The benefits have not ceased at the purely financial level. More subtle, but equally as important, benefits have been felt at a cultural level within BT. Internal audits have shown that people who use the intranet have higher morale because they feel better informed and more involved in the decision-making process. They feel empowered by having a degree of control over the information they receive as they are able to 'pull' it off the intranet rather then waiting for someone to 'push' it on to them. As an enabler of more flexible and effective working practices, BT's intranet applications have also helped BT to be the first major UK company to aim for 10 per cent of its office workforce working from home by the end of $1999-10,000$ teleworkers in the UK alone. The impact has also been external, with customers commenting on significantly improved service levels they receive from groups using the intranet, based on them being better informed.

\section{BT intranet's intangible benefits}

In August 1998, BT brought in the external research agency, NOP, to conduct a comprehensive satisfaction survey among BT's employees on their use of the intranet. The aim was to gain an understanding of how the intranet was being used in day-to-day operations and gauge the more intangible benefits that the system was delivering.

The report's key findings were positive and encouraging, reinforcing the more tangible financial benefits of an intranet and increasing the 
Leveraging knowledge

\section{Customers want self-service}

\section{Personalisation - the segment of one}

perceived ROI that technologies of this ilk can and do deliver to organisations. Overall satisfaction among employees received a mean score rating of 7.38 (out of a maximum of 10). Seventy-six per cent of respondents stated that their use of the intranet was increasing and 39 per cent were using the intranet more than five times daily.

The main uses of the intranet included searching for contact information (95 per cent), observing BT's share price (90 per cent), obtaining company-wide news ( 79 per cent), information on procedures/ processes (70 per cent) and employee briefings (60 per cent).

Users were also asked if they agreed with various statements regarding BT's intranet. Table 1 illustrates the corresponding answers.

Table 1: Employee opinions of BT's intranet

\begin{tabular}{|lrrr|}
\hline Would you say that the BT Intranet ... & Yes & No & Don't know \\
& $\%$ & $\%$ & $\%$ \\
\hline Helps you work more efficiently? & 85 & 9 & 6 \\
Makes your work more enjoyable? & 64 & 23 & 12 \\
Encourages sharing of information? & 86 & 6 & 7 \\
Makes you more self-sufficient? & 86 & 8 & 6 \\
Helps you cope better with the amount of information available? & 71 & 19 & 10 \\
\hline
\end{tabular}

\section{The Web as a channel}

BT has long used its website www.bt.com as a key communications vehicle for customers, partners and shareholders and has won a number of major awards for the site. During 1998 the site was extended considerably to become a powerful channel to market for a range of services, with 'hits' and transactions increasing monthly. During the past year, bt.com completed over a million transactions, a huge increase over the previous year, demonstrating that BT customers have a real appetite for 'self-service' via the Web and want to use this medium as well as more traditional channels. Customers are demanding a choice in the ways of interacting, communicating and transacting with BT - many will use several means - but the Web is becoming an increasingly important part of the mix for everything from routine enquiries and product purchases to real-time bill queries and service orders. Developments currently under way will further increase the ease of navigation, richness of information, range of services and extent of interactivity and individual personalisation available through bt.com.

\section{eBusiness in BT's supply chain}

BT has ensured that it has not stood still after these initial successes in eBusiness. The company is now looking towards streamlining its supply chain, producing leaner organisational structures and contacts with its suppliers. BT is one of the first companies in the UK to begin implementing BT MarketSite, a solution which will automate the procurement procedure for indirect goods and services, such as travel, computer hardware and software, stationery and maintenance services. 
Mellor

\section{Reducing purchase order costs from $£ 50$ to $£ 5$}

\section{Rapid business change}

\section{Building the networked 'knowledge economy'}

\section{Competitive opportunities}

Indirect goods are those used by businesses internally rather than for processing into resellable goods and services. The indirect goods market is massive in the UK, estimated to be worth around $£ 21 \mathrm{bn}$ in office equipment alone. Implementing an Internet-based procurement system will enable BT and its contracted suppliers to take advantage of the significant cost reductions offered by eBusiness over established trading methods.

The 'buyer' clicks on an intranet application on their PC screen and the whole process of checking authority levels, raising orders, identifying the right supplier, completing payment and managing delivery is handled automatically via a BT service on the Internet. BT is also trialling MarketSite with some of its major UK customers in preparation for wider availability, working with US partner and developer, CommerceOne.

\section{Where next for BT as an eBusiness?}

There can be no doubt that BT's first foray into eBusiness has been an unmitigated success. Both the financial and cultural metrics that were put in place at the project's inception have been delivered upon and surpassed faster than anyone could have predicted. But it doesn't end there. The rapid business change that we are experiencing marches on relentlessly, and BT must continually react and adapt to this change.

Having Europe's largest intranet up and running has placed BT at the forefront of corporate eBusiness development, but today's competitive business landscape shows that we cannot rest on our laurels.

\section{Conclusion}

The way in which companies operate, from sales, marketing and customer service right through the value chain to their internal processes and their relationships with business partners and suppliers, is undergoing radical change. Barriers to entry into previously unassailable markets are lowering, allowing agile new competitors to steal customers from old incumbents using the vastly lower cost structure of Internet selling. A traditional bank which took 600 years to win 900,000 customers is now faced with competitors like Tesco who achieved the same base in six months! This change is more profound than that instigated by the industrial revolution, and is fuelled by technological advances in computing and telecommunications. Let no one assume, however, that technology holds all the answers. Companies seeking to take advantage of electronic business should first look hard at the business priorities: how will they differentiate themselves in the emerging 'networked economy'; what are the primary opportunities for saving money, working more efficiently, creating new revenue or improving customer service? Only with these clearly prioritised goals in mind, plus the means of measuring progress towards them in a meaningful way (probably not traditional ROI measures) and the flexibility to adapt quickly as the market accelerates, should the practical answers be sought with a partner experienced in delivering technology for business advantage. It's often said that 'no one is making money on the Internet' - this may be true for many new ventures, but BT's experience has shown that with focused management, a clear vision of the competitive opportunities to be realised and a deep understanding of the technological enablers, there are very significant savings to be made and exciting new ways of driving up customer service and revenue. 